\section{Hormônios Tireóideos, UCPs e Termogênese}

\section{RESUMO}

Calor é um subproduto da transformação de energia, em suas diversas formas, durante a sintese e a utilização do ATP. Nos animais homeotérmicos, o calor derivado das funções biológicas - estando o organismo em repouso e à temperatura ambiente - é utilizado para manter o organismo próximo a $37^{\circ} \mathrm{C}$. Essa termogênese obrigatória está associada à ineficiência termodinâmica intrínseca mitocondrial, derivada da presença de proteínas desacopladoras (UCPs, uncoupling proteins). Durante a exposição ao frio, o organismo é capaz de gerar mais calor através da termogênese facultativa, por processos que também envolvem UCPs. Os hormônios tireóideos influenciam diretamente a expressão da UCP-1 e, indiretamente, a expressão das UCP-2 e UCP-3. Além disso, também aceleram o turnover de várias reações ou vias metabólicas cíclicas que levam a maior gasto de ATP e produção de calor. (Arq Bras Endocrinol Metab 2000;44/4: 281-289)

Unitermos: Transferência de energia; ATP: Termogênese; Hormônios tireóideos

\section{ABSTRACT}

Heat is a byproduct of the energy transformation in its various forms during the synthesis and utilization of ATP. In homeothermic animals the heat derived from the biological functions - at rest and at room temperature - is used to keep the body temperature close to $37^{\circ} \mathrm{C}$. This obligatory thermogenesis is associated to the intrinsic mitochondrial thermodynamic inefficiency caused by the presence of uncoupling proteins (UCPs). During cold exposure the body is capable of generating more heat by means of the facultative thermogenesis, a series of processes that also involves the function of UCPs. The thyroid hormones influence directly the expression of UCP-1 and indirectly the expression of UCP-2 and UCP-3. Furthermore, they also accelerate the turnover of several cyclical biochemical reactions and pathways that lead to greater ATP breakdown and energy expenditure. (Arq Bras Endocrinol Metab 2000;44/4: 28 1-289)

Keywords: Thyroid hormones; Thermogenesis; UCP; ATP

$\mathrm{C}$ ALOR É UM SUBPRODUTO DA TRANSFORMAÇÃO da energia em seus vários estados (1). Por exemplo, a energia química contida na gasolina é liberada de forma explosiva durante sua oxidação, sendo transformada no motor do automóvel em energia mecânica (trabalho) que movimenta o veículo. $O$ calor resultante da transformação de energia química em energia mecânica aquece o motor. A maioria $(-75 \%)$ da energia derivada da oxidação da gasolina é perdida na forma de calor. Ao contrário, num motor elétrico, mais de $90 \%$ da energia é transformada em trabalho, o que faz com que este tipo de motor esquente menos e seja mais econômico e eficiente do ponto de vista termodinâmico. revisão

Antonio C. Bianco

\author{
Departamento de Fisiologia e \\ Biofisica, Instituto de Ciências \\ Biomédicas, Universidade de \\ São Paulo, São Paulo, SP.
}


Em todos os animais ocorre um processo muito semelhante. A energia química contida nos substratos energéticos (alimentos) é liberada lentamente durante a oxidação dos açúcares e gorduras, sendo armazenada temporariamente na forma de ATP. A partir de então ocorre um novo processo de transformação energética resultando em trabalho biológico, e.g. transporte de íons, síntese de macromoléculas (lípides, proteínas, ácidos nucléicos), contração muscular e outros. Neste caso, também, o principal subproduto da transformação da energia é o calor. A eficiência termodinâmica do nosso organismo, à semelhança do motor a gasolina, é de cerca de $30 \%$.

A ineficiência termodinâmica no automóvel representa um gasto (\$) "desnecessário" a cada reabastecimento. Entretanto, a ineficiência dos seres vivos é importante e serve um propósito biológico: aquecer o organismo, otimizando o funcionamento das células, tecidos e sistemas. Do ponto de vista filogenético, essa ineficiência termodinàmica serviu como força evolutiva. Existe um degrau evolutivo bastante importante entre os animais pecilotérmicos ("sangue frio") e homeotérmicos ("sangue quente"): do ponto de vista termodinâmico, o organismo dos animais homeotérmicos é ainda mais ineficiente que os animais pecilotérmicos, o que faz com que estes consigam manter a temperatura corporal próxima dos $37^{\circ} \mathrm{C}$. Como resultado, temos melhor funcionamento enzimático, movimentos mais rápidos e mais prolongados, maior capacidade de adaptação às diversidades do meio ambiente, constituindo vantagem evolutiva sobre os animais pecilotérmicos (2).

Do ponto de vista bioquímico, a produção de calor nos seres vivos pode ser analisada como resultante da: (i) síntese de ATP ou (ii) hidrólise de ATP. A eficiência termodinâmica da síntese de ATP é de cerca de $65 \%$, ou seja, $\sim 35 \%$ da energia liberada durante a oxidação dos substratos energéticos (transformação de energia) é liberada na forma de calor. Entretanto, a molécula de ATP é um armazém intermediário de energia que deve ser novamente mobilizada (hidrólise do ATP) para que ocorra o trabalho biológico. A eficiência desta segunda etapa é menor ainda, de cerca de $40 \%$. Assim, a eficiência termodinâmica do nosso organismo é de cerca de 25-30\%.

Para a síntese de ATP, a energia proveniente do ciclo de Krebs é processada pela cadeia respiratória, sendo armazenada transitoriamente na forma de um potencial eletroquímico de prótons através da membrana mitocondrial interna. Como a membrana mitocondrial interna é relativamente impermeável aos prótons, as moléculas de ATP são geradas à medida que os prótons retornam à matriz mitocondrial, através da enzima ATP-sintase. Entretanto, existe um "vazamento" intrínseco de prótons para a matriz da mitocôndria, cujo retorno é acompanhado da liberação de calor ao invés da síntese de ATP. Admite-se que este "vazamento" mitocondrial de prótons seja da ordem de 30 a $40 \%$ (3).

A hidrólise de ATP, por sua vez, está associada ao trabalho biológico. Sempre que a célula realiza trabalho ocorre hidrólise de ATP e perda de energia na forma de calor.

Nesse sentido, fica claro que os mecanismos celulares e moleculares responsáveis pela produção de calor durante a síntese de ATP são distintos dos mecanismos envolvidos na hidrólise de ATP. Enquanto o primeiro tem relação com o funcionamento da mitocôndria, o segundo está intimamente relacionado com o trabalho celular, sendo influenciado diretamente pelo turnover de uma série de ciclos iônicos, de substratos e metabólicos, ou seja, de reações que levam ao gasto de ATP. Pode-se dizer, então, que quase todo calor biológico é decorrente, em última análise, dos processos que envolvem a síntese e a hidrólise do ATP (turnover). Quanto mais acelerado for o turnover de ATP, maior será a produção de calor.

Do ponto de vista fisiológico, admite-se que a produção de calor nos animais possa ser dividida em duas categorias: termogênese obrigatória e termogênese facultativa.

A termogênese obrigatória - BMR (basal metabolic rate, taxa de metabolismo basal) - é a somatória de todo o calor produzido no organismo, estando este em vigília e repouso, na temperatura ambiente e em jejum de pelo menos $12 \mathrm{~h}$. É o resultado da ineficiência intrínseca mitocondrial e do turnover de ATP, associado em grande parte a: ciclos celulares iônicos e de substratos, e.g. Na/K, Ca, ciclos da glicólise, particularmente nos tecidos excitáveis e renal; ciclos metabólicos, e.g. ciclo de Cori, lipólise/lipogênese, glicogenólise/glicogênese, particularmente no fígado e tecido adiposo; contração e relaxamento muscular derivado do trabalho muscular basal, particularmente os batimentos cardíacos, movimentos respiratórios, tônus da musculatura estriada e vasomotora, peristaltismo; e secreção basal de glândulas exócrinas e anexas ao tubo digestivo.

Apenas alguns animais têm a capacidade de modular a termogênese obrigatória, diminuindo a BMR durante o torpor ou hibernação. Durante o torpor observado em beija-flores, a temperatura e o metabolismo basais diminuem cerca de $40-50 \%$, reduzindo as necessidades energéticas durante a noite 
(3). Já na hibernação, a BMR pode cair muito abaixo do normal durante várias semanas do inverno e a temperatura corporal permanecer próxima à temperatura ambiente $\left(1-2^{\circ} \mathrm{C}\right.$ em alguns casos) (4).

A termogênese facultativa é todo o calor produzido além da BMR. É o resultado do aumento da ineficiência termodinâmica mitocondrial (ver abaixo) $\mathrm{e}$ do aumento do turnover de ATP associado, por exemplo, à contração muscular durante atividades diárias mínimas ou à prática de esportes. A termogênese facultativa também pode ser derivada de processos involuntários, tais como o tremor muscular (tiritação) associado à exposição ao frio. Entretanto, o que tem recebido maior atenção dos pesquisadores é a termogênese facultativa não-tiritação. Em pequenos mamíferos, esta ocorre principalmente na gordura marrom, enquanto nos mamíferos de grande porte, incluindo os seres humanos, sua origem ainda não está bem determinada.

A termogênese facultativa tem intensidade variável, dependendo da magnitude do estímulo desencadeador, e pode ser induzida em duas condições: (i) exposição ao frio, ou (ii) durante período de alimentação com dieta hipercalórica.

Durante exposição ao frio, o organismo perde maior quantidade de calor para o meio ambiente e, portanto, aumenta a produção de calor além da BMR para manter a temperatura corporal próxima a $37^{\circ} \mathrm{C}$. Da mesma forma, a dieta hipercalórica leva a um aumento da termogênese facultativa no sentido de eliminar, sob a forma de calor, o excesso de energia que de outra forma seria armazenado no organismo (5).

Um dos principais efeitos biológicos dos hormônios tireóideos é a aceleração do metabolismo energético e do turnover de ATP, com resultante transformação e consumo de energia e produção de calor. Nesse sentido, é interessante notar que a força evolutiva escolheu os hormônios tireóideos como mediadores da homeotermia. Apesar da glândula tireóide estar presente desde os vertebrados mais primitivos, apenas nos animais homeotérmicos os hormônios tireóideos são capazes de estimular a produção de calor. Não devemos pensar, entretanto, que eles sejam inativos nos demais animais. Ao contrário, os hormônios tireóideos são extremamente importantes nos animais pecilotérmicos, como pode ser verificado através da promoção da metamorfose em anfíbios. Entretanto, a capacidade de estimular a produção de calor é uma aquisição mais recente e marca a transição para a homeotermia (6). Por exemplo, mamíferos com hipotircoidismo, incluindo o ser humano, podem apresentar hipotermia e intolerância ao frio, perdendo parte da homeotermia e capacidade de adaptação ao meio ambiente.
Apesar dos efeitos termogênicos dos hormônios tireóideos serem reconhecidos desde o início deste século, o conhecimento detalhado dos mecanismos celulares e moleculares envolvidos ainda nos escapa (78 ). Na década de 50 , estudos pioneiros demostraram que a tireoidectomia resultava em diminuição da BMR de ratos e que a administração de tiroxina $\left(\mathrm{T}_{4}\right)$ causava rápida elevação da $\mathrm{BMR}$, chegando a valores 2-3 vezes mais altos do que em animais intactos. Ratos tireoidectomizados não morrem, mas apresentam discreta hipotermia se mantidos à temperatura ambiente. Também notou-se que o aumento do consumo de $\mathrm{O}_{2}$ dependia do tecido estudado; o coração e a musculatura esquelética eram os que mais respondiam ao $\mathrm{T}_{4}$, enquanto os testículos, o cérebro e o baço não respondiam. A partir de então, comprovou-se a capacidade dos hormônios tireóideos de aumentar a termogênese obrigatória, a BMR. Mais recentemente (década de 60), reconheceu-se a importância dramática dos hormônios tireóideos para a termogênese facultativa desencadeada durante exposição ao frio. Ratos intactos suportam perfeitamente baixas temperaturas, ativando a termogênese facultativa. Por outro lado, ratos tiroidectomizados não conseguem ativar a termogênese facultativa, morrendo algumas horas após exposição a baixas temperaturas. Dessa forma, admitese que os hormônios tireóideos participem do controle da termogênese obrigatória e também do desencadeamento e da manutenção da termogênese facultativa.

\section{TERMOGENESE OBRIGATÓRIA}

\section{Sintese de ATP}

De acordo com a teoria químio-osmótica, desenvolvida na década de 60 , a energia proveniente do ciclo de Krebs é transferida, como poder redutor, às moléculas de NADH e FADH ${ }^{2}$. Estas moléculas, por sua vez, são oxidadas na cadeia respiratória, resultando em transferência da energia extraída dos substratos energéticos - na forma de elétrons energizados - para os diferentes componentes da cadeia respiratória. Os diferentes componentes utilizam a energia desses elétrons para bombear prótons para fora da matriz mitocondrial, criando um poderoso potencial eletroquímico que armazena temporariamente a energia na forma de energia potencial. Os prótons retornam para a matriz mitocondrial, a favor do seu gradiente elétrico e de concentração, através da ATP-sintase. A cada 2 ou 3 prótons que passam por essa enzima observa-se a síntese de 1 molécula de ATP. Dessa forma, pode-se dizer que a oxidação dos substratos energéticos encontra-se acoplada à síntese de ATP. 
Uma usina hidroelétrica funciona de forma muito semelhante. Devido à altura da barragem, a água represada a montante desta (prótons extramitocondriais) armazena energia potencial. Para ganhar o rio, abaixo da barragem (matriz mitocondrial), a água armazenada passa pelas turbinas (ATP-sintase). Nesse momento, a turbina entra em funcionamento e, ao girar, transforma energia potencial em energia elétrica (fosforilação do ADP em ATP). Entretanto, esse processo não é ideal do ponto de vista termodinâmico, sendo que muito da energia potencial, mesmo passando pela turbina, é perdida sob a forma de calor e ruído. Ao observarmos a estrutura de uma barragem hidroelétrica vamos notar a existência de um vertedouro que funciona paralelamente às turbinas. Essa estrutura permite a passagem livre de água pela barragem, sem que esta passe obrigatoriamente pelas turbinas. Quando a água passa pelo vertedouro, toda a energia potencial é perdida na forma de calor e ruído, sem que haja transformação de energia potencial em energia elétrica. Dessa forma, os técnicos da usina podem controlar a eficiência termodinâmica da barragem. Ao regular o fluxo de água pelo vertedouro pode-se controlar quanto da energia potencial armazenada é transformada, a cada momento, em energia elétrica e quanto é perdida sob outras formas.

Voltando ao funcionamento mitocondrial, vamos verificar que medidas experimentais do potencial eletroquímico de prótons e síntese de ATP revelam a existência de um vazamento de prótons para o interior mitocondrial sem que passem pela ATP-sintase (3). Isso ocorre de forma muito semelhante à passagem da água pelo vertedouro. Quando os prótons retornam à matriz mitocondrial sem passar pela ATPsintase, a energia potencial armazenada é perdida sob a forma de calor. Estima-se que este vazamento de prótons possa atingir até $40 \%$ da energia potencial armazenada, resultando num desacoplamento mitocondrial fisiológico.

Procurando-se a origem desse desacoplamento mitocondrial, recentemente foram identificadas algumas proteínas, que facilitam a passagem de prótons do espaço intermembranoso para a matriz mitocondrial, conhecidas como UCP-2, UCP-3 e UCP-4. Na verdade, essas proteínas são homólogas à UCP-1 que foi descrita há algumas décadas na gordura marrom e que participa da termorregulação de pequenos mamíferos (9). A UCP-1 acelera muitas vezes o retorno de prótons para a matriz mitocondrial, fazendo com que a maior parte da energia proveniente do ciclo de Krebs e, por conseguinte, da oxidação dos substratos energéticos, seja perdida na forma de calor. A UCP-l não é expressa fora da gordura marrom, mas a descoberta dessas proteínas homólogas (UCP-2 e 4) explica o desacoplamento fisiológico das mitocôndrias de fígado, tecido muscular esquelético, coração, cérebro e tecido adiposo branco.

Os ácidos graxos são importantes para o funcionamento das UCPs; na sua ausência o desacoplamento mitocondrial não ocorre (10). Na verdade, admite-se que os ácidos graxos sejam os agentes catalisadores da passagem de prótons para a matriz mitocondrial, através de um movimento de "flip-flop" entre as duas faces da membrana mitocondrial $(11,12)$. Na face externa eles estariam protonados e na face interna eles perderiam o próton para a matriz mitocondrial. O papel das UCPs nesse caso é acelerar muitas vezes o movimento de "flip-flop", aumentando a corrente de prótons para a matriz mitocondrial. De fato, esse mecanismo faz sentido se pensarmos que os ácidos graxos são rapidamente transferidos para o interior mitocondrial pela enzima CPT e, em seguida, oxidados, resultando em aumento do potencial eletroquímico de prótons na mitocôndria. Dessa forma, o desacoplamento mitocondrial causado pelos próprios ácidos graxos poderia, entre outras coisas, servir para regular a intensidade do potencial eletroquímico a que a ATP-sintase está sendo submetida a cada momento, da mesma forma como os técnicos da hidroelétrica controlam, momento a momento, a quantidade de água que passa pela turbina ou pelo vertedouro. Assim, admite-se que a existência dessas UCPs seja intrínseca ao funcionamento mitocondrial, mantendo o potencial mitocondrial em condições ótimas para o funcionamento da ATP-sintase.

A administração de hormônios tireóideos resulta em desacoplamento mitocondrial que talvez possa ser explicado pelo aumento das UCPs 2 e 3 , no figado e na musculatura esquelética, induzido por esses hormônios (13). Num primeiro momento, deu-se muita importância a esses achados, acreditando-se que a maior parte dos efeitos termogênicos dos hormônios tireóideos fosse derivada desse mecanismo. A idéia é que os hormônios tireóideos poderiam dessa forma regular a eficiência termodinâmica da mitocôndria. Entretanto, a incapacidade de reprodução convincente do aumento das UCPs pelo T3 em sistemas isolados (cultura de células) confirma que, na verdade, a administração de hormônios tireóideos promove $o$ desacoplamento mitocondrial e aumenta as UCPs 2 e 3 indiretamente, através de seu efeito lipolítico, aumentando a chegada de ácidos graxos aos diferentes tecidos. Confirmando essa visão, verificou-se que a lipólise decorrente do jejum promove forte estimulação das 
UCPs 2 e $3 \mathrm{em}$ diversos tecidos. Pelo menos no tecido adiposo, os ácidos graxos estimulam a expressão dos genes das UCPs 2 e 3 através da interação com receptores $\operatorname{PPAR}(14,15)$. Mais estudos são necessários para se estabelecer a participação desses mecanismos nos efeitos termogênicos dos hormônios tireóideos.

Outra forma de se controlar a eficiência termodinâmica da mitocôndria é através da enzima $\alpha$ glicerol-fosfato-desidrogenase ( $\alpha$-GPD). Esta enzima está associada ao complexo 2 da cadeia respiratória e catalisa o aproveitamento do NADH citosólico na cadeia respiratória. Normalmente, o NADH citosólico é transportado para a matriz mitocondrial através do shunt malato/aspartato, sendo oxidado pelo complexo I da cadeia respiratória e gerando 3 moléculas de ATP. Ocorre que, se o $\mathrm{NADH}$ citosólico entrar na cadeia respiratória pelo complexo 2 (através da $\alpha$-GPD), cada molécula de NADH dará origem a apenas 2 moléculas de ATP, sendo a energia equivalente a 1 molécula de ATP perdida na forma de calor. Assim sendo, quanto maior a atividade da enzima $\alpha$-GPD, menor será a eficiência termodinâmica do aproveitamento do NADH citosólico e, também, de toda a mitocôndria.

Desde a década de 60 sabe-se que os hormônios tireóideos aumentam a atividade da $\alpha$-GPG mitocondrial, nos mesmos tecidos em que aumenta o consumo de oxigênio. Na verdade, em células hepáticas existe boa correlação entre indução da atividade $\alpha$-GPD e do consumo de oxigênio. Entretanto, a importância desta via não deve ser super-valorizada, uma vez que a disposição de NADH citosólico é limitada, principalmente pelo funcionamento da glicólise. Talvez, no tecido muscular esquelético, esta via tenha uma importância especial, principalmente nos músculos de contração rápida, ricos em fibras do tipo II, cuja principal fonte energética é a glicólise anaeróbica. Mais recentemente, o gene da $\alpha$-GPD mitocondrial foi clonado, confirmando-se que os níveis correspondentes de mRNA são elevados pelos hormônios tireóideos em diversos tecidos, incluindo o miocárdio, musculatura esquelética e tecido adiposo (16).

\section{Hidrólise de ATP}

Nem toda a energia armazenada nas ligações de fosfato da molécula de ATP é aproveitada para acele$\mathrm{rar} /$ promover reações enzimáticas. Uma fração substancial é perdida na forma de calor quando o ATP é hidrolizado. Assim, qualquer reação que resulte em hidrólise de ATP também promove a termogênese, por dois mecanismos: calor liberado como resultado direto da hidrólise do ATP; e indiretamente, calor liberado durante a regeneração da molécula de ATP, devido à ineficiência termodinâmica mitocondrial.
O ATP é amplamente utilizado como fonte energética em todas as células. Dessa forma, existem algumas reações ou seqüência de reações que gastam quantidades substanciais de ATP e que são alvo dos hormônios tireóideos. Os ciclos iônicos são um exemplo. O funcionamento dos transportadores $\mathrm{de}^{\mathrm{Na}^{+} / \mathrm{K}^{+}}$ existentes na membrana celular resulta num consumo energético substancial, uma vez que o sódio vaza constantemente para o interior celular e o potássio para o meio extracelular. Isso caracteriza um processo cíclico que faz com que a manutenção das concentrações iônicas nos dois lados da membrana se dê às custas da hidrólise contínua de ATP. Em células excitáveis, como tecido nervoso, ou em células com grande atividade transportadora, como o epitélio renal ou intestinal, este gasto constante de ATP ganha magnitude ainda maior. Os hormônios tireóideos estimulam o turnoper do transportador $\mathrm{Na}^{+} / \mathrm{K}^{+}$, aumentando o gasto de ATP e a produção de calor. $\mathrm{Na}$ última década, verificou-se que o gene desse transportador é estimulado pelos hormônios tireóideos, explicando o aumento do número das unidades funcionais $\mathrm{Na}^{+} / \mathrm{K}+$ ATPase em tecidos de animais com tireotoxicose $(17,18)$.

Um outro exemplo é o tecido muscular esquelético. $\mathrm{O}$ ciclo do cálcio (entre o citosol e o retículo sarcoplasmático), responsável pela contração e relaxamento muscular, consome grande quantidade de energia. Também aqui, os hormônios tireóideos têm papel fundamental, regulando a expressão dos genes que codificam as diferentes isoformas da cadeia pesada da miosina (MHC) (19) e do transportador de cálcio (SERCA) $(20,21)$. O T3 estimula a expressão da isoforma de $\mathrm{MHC}$ com maior atividade catalítica e, portanto, maior atividade ATPásica. Da mesma forma, o T3 estimula a expressão do gene SERCA e aumenta o número de unidades funcionais desta enzima no retículo sarcoplasmático, aumentando o potencial de cálcio no seu interior. Como resultado, a cada ciclo de contração/relaxamento, a quantidade de cálcio mobilizada é maior e, consequentemente, maior o gasto de ATP. Esse mecanismo é tão poderoso que alguns peixes conseguem manter a temperatura cerebral acima da temperatura da água graças a um órgão muscular retro-orbital, bastante especializado, rico em retículo sarcoplasmático e SERCA.

Existem inúmeros outros ciclos semelhantes a estes, envolvendo íons, intermediários metabólicos e substratos energéticos (ciclos de substratos), cuja velocidade também é estimulada pelos hormônios tireóideos, e.g. frutose-6-fosfato/frutose-1,6-bifosfato, ciclo de Cori, lipólise/lipogênese (7), glico- 
genólise/glicogênese, proteólise/síntese protéica, reabsorção/formação óssea (22) e outros. E importante notar que a estimulação do turnover desses ciclos resulta em apenas pequenas mudanças dos estoques de substratos envolvidos, dependendo da intensidade $\mathrm{e}$ duração do estímulo. Entretanto, todos resultam em aumento do gasto de ATP e, por conseguinte, produção de calor.

Dessa forma, não se pode dizer que existe um mecanismo único ou via principal responsável pelos efeitos termogênicos dos hormônios tireóideos no aumento do turnover de ATP e suas conseqüências para a BMR. O que existe é uma somatória de pequenos efeitos estimulantes no turnoper de reações espalhadas ao longo de todo o mapa metabólico, resultando em ativação da síntese e degradação de ATP.

\section{Termogênese Facultativa}

A termogênese facultativa é controlada basicamente pelo hipotálamo, sendo o sistema nervoso autônomo simpático o principal sistema mediador desses mecanismos. A noradrenalina (NA) é a principal molécula envolvida, tendo-se estudado muito os efeitos biológicos resultantes da interação com os receptores beta-adrenérgicos, particularmente os do tipo $\beta_{3}$. Como já salientado em relação ao BMR, os mecanismos que desencadeiam a termogênese facultativa são distintos e podem estar associados à síntese ou à hidrólise do ATP.

$O$ controle da eficiência termodinâmica da mitocôndria também é muito importante na termogênese facultativa. Este mecanismo foi identificado, primeiramente, na gordura marrom e depende, basicamente, da expressão única nesse tecido da UCP-I, cujo funcionamento é semelhante à das outras UCPs (23). Em pequenos roedores, a gordura marrom é fundamental para a manutenção da temperatura corporal durante exposição ao frio. Por exemplo, animais com knockout do gene da UCP-1 ou destruição programada da gordura marrom apresentam hipotermia e intolerância ao frio (24). O funcionamento deste tecido é basicamente regulado pela NA, liberada pelos numerosos terminais simpáticos nesse tecido, mas pode ser influenciado por inúmeros outros hormônios ou fatores metabólicos $(25,26)$. Durante alguns minutos de estimulação da NA, a gordura marrom pode aumentar sua temperatura $\mathrm{em}$ até $5^{\circ} \mathrm{C}(27)$.

A gordura marrom também é alvo dos hormônios tireóideos (28). Este tecido apresenta grande número de receptores de $\mathrm{T}_{3}$ que se encontram $70 \%$ ocupados à temperatura ambiente e $\sim 100 \%$ ocupados durante exposição do animal ao frio. $\mathrm{Na}$ verdade, a gordura marrom dispõe de um mecanismo próprio gerador de $\mathrm{T}_{3}$, graças à atividade local da enzima desiodase do tipo II, D2. A atividade dessa enzima e a concentração de $T_{3}$ aumentam, $\sim 50$ e 3 vezes, respectivamente, durante ativação simpática do tecido adiposo marrom, resultando em aumento do impacto local do $\mathrm{T}_{3}$, sem que a concentração plasmática de $\mathrm{T}_{3}$ seja afetada (29). Dessa forma, a ativação simpática da gordura marrom resulta em "hipertireoidismo" local e aumento da produção de calor.

A expressão do gene da UCP-1 (transcrição e estabilização do mRNA) e a concentração tecidual dessa proteína são reguladas positivamente pelos hormônios tireóideos (30-34). Enquanto a transcrição gênica da UCP-l depende do sinergismo entre $\mathrm{T}_{3} \mathrm{e}$ $A M P c, o T_{3}$ é capaz de promover a estabilização da molécula de mRNA-UCP-1 e um aumento da UCP mitocondrial, mesmo quando o tônus simpático está minimizado, i.e. durante aclimatação à termoneutralidade ou bloqueio farmacológico com propranolol ou reserpina. Admite-se que nas primeiras horas de exposição ao frio predomine o efeito transcricional, enquanto a estabilização da molécula de mRNA-UCP seja o mecanismo predominante a partir de $12 \mathrm{~h}$ de exposição continuada à temperatura de $4^{\circ} \mathrm{C}$, o que jus tifica o aumento prolongado, em 3 a 4 vezes, dos níveis de mRNA-UCP-1.

O funcionamento da UCP-1 também depende dos ácidos graxos e a gordura marrom é o tecido com maior capacidade lipogênica do organismo. Nas primeiras horas de ativação simpática da gordura marrom ocorre um predomínio da lipólise sobre a lipogênese, ativando a UCP-1 e o desacoplamento da cadeia respiratória (35-38). Os estoques de gordura do tecido chegam praticamente a zero. Entretanto, com o aumento rápido da ocupação dos receptores nucleares de $T_{3}$ e do impacto do $T_{3}$ nesse tecido, ocorre um aumento proporcional da lipogênese local que, atingindo um equilíbrio com a lipólise, restabelece os estoques teciduais de gordura e assegura a capacidade termogênica do tecido.

É interessante notar que a expressão e o funcionamento das UCPs no tecido muscular esquelético são controlados pelos ácidos graxos circulantes (39), o que é influenciado, basicamente, pelo estado nutricional e pela atividade da lipase hormônio sensível. Por exemplo, no jejum, devido à estimulação da lipólise do tecido adiposo branco, a concentração plasmática de ácidos graxos aumenta e isso estimula a expressão das UCPs no tecido muscular esquelético. Na gordura 
marrom, por outro lado, ambos os processos ocorrem no mesmo tecido: lipólise e desacoplamento da cadeia respiratória. A concentração de ácidos graxos é regulada basicamente pela lipólise local e, também, pela capacidade de ressíntese de triglicérides. Ambos os processos são influenciados positivamente pelos hormônios tireóideos.

Humanos têm muito pouca gordura marrom. $\mathrm{O}$ principal sítio de termogênese facultativa do nosso organismo parece ser o tecido muscular esquelético, mesmo no estado de repouso. Correspondendo a cerca de $40 \%$ da massa corporal, mesmo um pequeno aumento da termogênese muscular pode contribuir de forma importante para todo o organismo. Principalmente à luz de achados recentes de que a UCP-3 é ricamente expressa no músculo e é estimulada pelos hormônios tireóideos.

A atividade motora das pequenas atividades diárias ou da prática de esportes e a tiritação muscular durante exposição ao frio são os principais mecanismos termogênicos decorrentes da hidrólise de ATP. A tiritação muscular no ser humano é particularmente importante na manutenção da temperatura corporal durante exposição ao frio.

A termogênese facultativa pode ser desencadeada pela exposição ao frio ou pela dieta hipercalórica. Os hormônios tireóideos são fundamentais para o desencadeamento e sustentação da termogênese induzida pelo frio. Entretanto, a falta destes hormônios não parece ser limitante para a termogênese induzida pela dieta. Ratos com hipotireoidismo, alimentados com dieta hipercalórica, aumentam o consumo de oxigênio e comportam-se da mesma forma que ratos intactos, alimentados com a mesma dieta. A quantidade de gordura corporal, durante alimentação com dieta hipercalórica, aumenta igualmente nos animais intactos e tiroidectomizados (40).

$\mathrm{Na}$ verdade, a termogênese induzida pela dieta parece estar presente em vertebrados inferiores, mesmo naqueles em que, sabidamente, os hormônios tireóideos não exercem efeitos termogênicos. Esse tipo de termogênese provavelmente foi uma aquisição muito antiga na escala evolutiva $\mathrm{e}$ independe dos hormônios tireóideos. Por outro lado, o aparecimento da termogênese induzida pelo frio é mais recente (aves), sendo absolutamente dependente dos hormônios tireóideos.

\section{CONCLUSŌES}

Os animais homeotérmicos apresentam maior BMR que animais pecilotérmicos e têm a capacidade de aumentar ainda mais a produção de calor através da termogênese facultativa desencadeada pelo frio. Ambos os processos baseiam-se em mecanismos termogênicos que ocorrem durante a síntese (UCPs) e a utilização da molécula de ATP (trabalho celular). Os hormônios tireóideos são termogênicos. Aumentam per se a BMR e interagem com o sistema nervoso simpático no sentido de promover a termogênese facultativa desencadeada pelo frio. Também atuam no tecido muscular esquelético, aumentando o potencial deste para produzir calor durante o repouso ou a contração muscular. Tanto a eficiência termodinâmica da síntese de ATP quanto o gasto de ATP são influenciados pelos hormônios tireóideos através de múltiplos mecanismos. Por outro lado, a termogênese facultativa desencadeada pela dieta parece não depender dos hormônios tireóideos, seus mediadores incluem as UCPs no tecido muscular esquelético e adiposo branco.

\section{REFERÊNCIAS}

1. Sonntag RE, Borgnakke C, Van Wylen GJ. Work and heat. In: RE Sonntag, C Borgnakke, GJ Van Wylen, eds. Fundamentals of Thermodynamics. John Wiley \& Sons, Inc., New York, 1998:55-76.

2. Randal E, Burggren W. French K. Using energy: meeting environmental challenges. In: E Randal, W Burggren, $K$ French, eds. Eckert Animal Physiology. W H Freeman Co., New York, 1997:665-723.

3. Brand MD, Brindle KM, Buckingham JA, Harper JA, Rolfe DF, Stuart JA. The significance and mechanism of mitochondrial proton conductance (In Process Citation). Int J Obes Relat Metab Disord 1999:23(Suppl 6):S4-11.

4. Speakman JR, Rowland A. Preparing for inactivity: how insectivorous bats deposit a fat store for hibernation. Proc Nutr Soc 1999:58:123-31.

5. Rothwell NJ, Stock MJ, Stribling D. Diet-induced thermogenesis. Pharmacol Ther 1982;17:251-68.

6. Weirich RT, Schwartz HL, Oppenheimer JH. An analysis of the interrelationship of nuclear and plasma trilodothyronine in the sea lamprey, lake trout, and rat: evolutionary considerations. Endocrinology 1987:120:664-77.

7. Oppenheimer JH, Schwartz HL, Lane JT, Thompson MP. Functional relationship of thyroid hormone-induced lipogenesis, lipolysis, and thermogenesis in the rat. J Clin Invest 1991:87:125-32.

8. Oppenheimer JH, Schwartz HL, Mariash $\mathrm{CN}$, Kinlaw WB, Wong NC. Freake HC. Advances in our understanding of thyroid hormone action at the cellular level. Endocr Rev 1987:8:288-308.

9. Bouillaud F. UCP1, UCP2 and UCP3: are they true uncouplers of respiration?. Int J Obes Relat Metab Disord 1999:23(Suppl 6):S19-23.

10. Himms-Hagen J, Harper ME. Biochemical aspects of the uncoupling proteins: view from the chair. Int J Obes Relat Metab Disord 1999:23(Suppl 6):S30-2. 
11. Gonzalez-Barroso MM, Fleury C, Jimenez MA, Sanz JM, Romero A, Bouillaud $F$, et al. Structural and functional study of a conserved region in the uncoupling protein UCPI: the three matrix loops are involved in the control of transport. J Mol Biol 1999;292: 137-49.

12. Jezek $P$, Engstova $H$, Zackova $M$, Vercesi $A E$, Costa $A D$, Arruda $P$, et al. Fatty acid cycling mechanism and mitochondrial uncoupling proteins, Biochim Biophys Acta 1998; 1365:319-27.

13. Jekabsons MB, Gregoire FM, Schonfeld-Warden NA, Warden $\mathrm{CH}$, Horwitz BA. T(3) stimulates resting metabolism and UCP-2 and UCP-3 mRNA but not nonphosphorylating mitochondrial respiration in mice. Am J Physiol 1999:277:E380-9.

14. Aubert J, Champigny O, Saint-Marc P, Negrel R, Collins $S$, Ricquier D, et al. Up-regulation of UCP-2 gene expression by PPAR agonists in preadipose and adipose cells Biochem Biophys Res Commun 1997;238:606-11.

15. Brun S, Carmona MC, Mampel T, Vinas O, Giralt M, Iglesias $R$, et al. Activators of peroxisome proliferator-activated receptor-alpha induce the expression of the uncoupling protein-3 gene in skeletal muscle: a potential mechanism for the lipid intake-dependent activation of uncoupling protein-3 gene expression at bith. Diabetes 1999;48: 1217-22.

16. Gong DW, BI S, Weintraub BD, Reitman M. Rat mitochondrial glycerol-3-phosphate dehydrogenase gene: multiple promoters, high levels in brown adipose tissue, and tissue-specific regulation by thyroid hormone. DNA Cell Biol 1998; 17:301-9.

17. Desai-Yajnik V, Zeng J, Omori K, Sherman J, Morimoto T, The effect of thyroid hormone treatment on the gene expression and enzyme activity of rat liver sodium-potassium dependent adenosine triphosphatase. Endocrinology 1995:136:629-39.

18. Folke $M$, Sestoft $L$. Thyroid calorigenesis in isolated, perfused rat liver: minor role of active sodium-potassium transport. J Physiol (Lond) 1977:269:407-19.

19. Canepari M, Cappelli V, Pellegrino MA, Zanardi MC, Reggiani $\mathrm{C}$. Thyroid hormone regulation of $\mathrm{MHC}$ isoform composition and myofibrillar ATPase activity in rat skeletal muscles. Arch Physiol Biochem 1998;106:308-15.

20. Nunes MT, Bianco AC. Migala A, Agostini B, Hasselbach $W$. Thyroxin induced transformation in sarcoplasmic reticulum of rabbit soleus and psoas muscles. $\mathbf{Z}$ Naturforsch (C) 1985:40:726-34.

21. Sayen MR, Rohrer DK, Dillmann WH. Thyroid hormone response of slow and fast sarcoplasmlc reticulum $\mathrm{Ca}^{2+}$ ATPase mRNA in striated muscle. Mol Cell Endocrinol $1992 ; 87: 87-93$

22. Gouveia $\mathrm{CH}$, Jorgetti $\mathrm{V}$, Bianco AC. Effects of thyroid hormone administration and estrogen deficiency on bone mass of female rats. J Bone Miner Res 1997; 12:2098-107.

23. Nicholls DG, Locke RM. Thermogenic mechanisms in brown fat. Physiol Rev 1984;64: 1-64.

24. Lowell BB, V SS, Hamann A, Lawitts JA, Himms-Hagen J, Boyer BB, et al. Development of obesity in transgenic mice after genetic ablation of brown adipose tissue (see comments). Nature 1993:366:740-2.

25. Moriscot A, Rabelo R, Bianco AC. Corticosterone inhibits uncoupling protein gene expression in brown adipose tissue. Am J Physiol 1993;265:E81-7.

26. Carvalho SD, Bianco AC, Silva JE. Effects of hypothyroldism on brown adipose tissue adenylyl cyclase activity. Endocrinology 1996; 137:5519-29.

27. Ribeiro MO, Cristoffolete M, Branco M, Negrão N, Bianco AC, Influence of hypothyroidism and uncoupling protein (UCP) in brown adipose tissue heat production in response to norepinephrine. Program, 71st Annual Meeting of the American Thyroid Association, Portland OR, 1998, p 104 .

28. Bianco AC, Silva JE. Nuclear 3,5,3'-trilodothyronine (T3) in brown adipose tissue: receptor occupancy and sources of T3 as determined by in vivo techniques. Endocrinology $1987 ; 120: 55-62$

29. Bianco AC, Silva JE. Cold exposure rapidly induces virtual saturation of brown adipose tissue nuclear T3 receptors. Am J Physiol 1988;255:E496-503.

30. Bianco AC, Silva JE. Intracellular conversion of thyroxin to triiodothyronine is required for the optimal thermogenic function of brown adipose tissue. J Clin Invest 1987;79:295-300.

31. Bianco $A C$, Sheng $X Y$, Silva JE, Triiodothyronine amplifies norepinephrine stimulation of uncoupling protein gene transcription by a mechanism not requiring protein synthesis. J Biol Chem 1988;263: 18168-75.

32. Rehnmark S, Bianco AC, Kieffer JD, Silva JE. Transcriptional and posttranscriptional mechanisms in uncoupling protein mRNA response to cold. Am J Physiol 1992;262:E58-67.

33. Bianco AC, Kieffer JD, Silva JE. Adenosine 3',5'monophosphate and thyroid hormone control of uncoupling protein messenger ribonucleic acid in freshly dispersed brown adipocytes. Endocrinology 1992; 130:2625-33.

34. Branco M. Ribeiro M, Negrao N, Bianco AC. 3,5,3'-Trilodothyronine actlvely stimulates UCP in brown fat under minimal sympathetic activity. Am J Physiol 1999:276:E179-87.

35. Bianco AC, Carvalho SD, Carvalho CR, Rabelo R, Moriscot AS. Thyroxin 5'-delodination mediates norepinephrine-induced lipogenesis in dispersed brown adipocytes. Endocrinology 1998;139:571-8.

36. Bianco AC, Silva JE. Optimal response of key enzymes and uncoupling protein to cold in BAT depends on loca T3 generation. Am J Physiol 1987;253:E255-63.

37. Carvalho SD, Kimura ET, Bianco AC, Silva JE. Central role of brown adipose tissue thyroxin 5'-deiodinase on thyroid hormone-dependent thermogenic response to cold. Endocrinology 1991:128:2149-59.

38. Carvalho SD, Negrao N, Bianco AC. Hormonal regulation of malic enzyme and glucose-6-phosphate dehydrogenase in brown adipose tissue. Am J Physiol 1993;264:E874-81. 
39. Boss O, Samec S, Kuhne F, Bijlenga P, AssimacopoulosJeannet $F$, Seydoux J, et al. Uncoupling protein-3 expression in rodent skeletal muscle is modulated by food intake but not by changes in environmental temperature. J Biol Chem 1998;273:5-8.

40. Curcio C, Lopes AM, Ribeiro MO, Francoso OA Jr., Carvalho SD, Lima FB, et al. Development of compensatory thermogenesis in response to overfeeding in hypothyroid rats. Endocrinology 1999; 140:3438-43.

\section{Endereço para correspondência:}

Antonio C. Bianco

Depto. de Fisiologia e Biofísica

ICB - USP

Av. Prof. Lineu Prestes 1524, sala 140

Fax: (011) 818-7285

e.mail: acbianco@usp.br 